OPEN ACCESS

Edited by:

Peter Sebastian Azzopardi,

Burnet Institute, Australia

Reviewed by:

Joanne C. Enticott,

Monash University, Australia

Pradeep Nair,

Central University of Himachal

Pradesh, India

${ }^{*}$ Correspondence:

Terryann C. Clark

t.clark@auckland.ac.nz

Specialty section:

This article was submitted to

Public Health Education and

Promotion,

a section of the journal

Frontiers in Public Health

Received: 04 May 2018

Accepted: 19 October 2018

Published: 13 November 2018

Citation:

Williams AD, Clark TC and Lewycka S

(2018) The Associations Between

Cultural Identity and Mental Health

Outcomes for Indigenous Māori Youth

in New Zealand.

Front. Public Health 6:319.

doi: 10.3389/fpubh.2018.00319

\section{The Associations Between Cultural Identity and Mental Health Outcomes for Indigenous Māori Youth in New Zealand}

\author{
Ashlea D. Williams, Terryann C. Clark ${ }^{*}$ and Sonia Lewycka \\ The School of Nursing, Faculty of Medical Health Sciences, University of Auckland, Auckland, New Zealand
}

Objectives: To explore the relationships between Māori cultural identity, ethnic discrimination and mental health outcomes for Māori youth in New Zealand.

Study Design: Nationally representative, anonymous cross-sectional study of New Zealand secondary school students in 2012.

Methods: Secondary analysis of Māori students $(n=1699)$ from the national Youth'12 secondary school students survey was undertaken. Theoretical development and exploratory factor analysis were undertaken to develop a 14-item Māori Cultural Identity Scale (MCIS). Māori students reporting > 8 items were classified as having a strong MCIS. Prevalence of indicators were reported and logistic regression models were used to explore how wellbeing (WHO-5), depressive symptoms (Reynolds Adolescent Depression Scale-SF), and suicide attempts were associated with the MCIS.

Results: After adjusting for age, sex, ethnic discrimination and NZ Deprivation Index (NZDep), a strong Māori cultural identity (MCIS) was associated with improved wellbeing scores (OR 1.53, 95\% Cl 1.18-2.01) and fewer depressive symptoms (OR 0.53, 95\% $\mathrm{Cl}$ 0.38-0.73). Experiencing discrimination was associated with poorer wellbeing scores (OR 0.50, 95\% Cl 0.39-0.65), greater depressive symptoms (OR 2.2, 95\% Cl 1.55-3.18), and a previous suicide attempt (OR 2.47, 95\% Cl 1.71-3.58). Females less frequently reported good ( $\mathrm{WHO}-5$ ) wellbeing (OR 0.33, 95\% Cl 0.26-0.42), increased (RADS-SF) depressive symptoms $(2.61,95 \% \mathrm{Cl} 1.86-3.64)$ and increased suicide attempts [OR 3.35 (2.07-5.41)] compared to males. Wellbeing, depressive symptoms and suicide attempts did not differ by age or neighborhood level socio-economic deprivation, except those living in neighborhoods characterized as having medium level incomes, were less likely to have made a suicide attempt (OR 0.49, 95\% Cl 0.27-0.91).

Conclusions: Māori youth who have a strong cultural identity were more likely to experience good mental health outcomes. Discrimination has a serious negative impact on Māori youth mental health. Our findings suggest that programmes, policies and practice that promote strong cultural identities and eliminate ethnic discrimination are required to improve mental health equity for Māori youth.

Keywords: Māori, youth, cultural identity, mental health, ethic discrimination, indigenous, suicide, cultural programming 


\section{INTRODUCTION}

Rangatahi Mãori, the indigenous youth of New Zealand experience significantly poorer mental health outcomes compared to Pākehā/NZ European youth (1-7). Rates of serious depressive symptoms are similar (Māori 13.9\%, NZ European 12.1\%), but Māori youth report considerably higher prevalence of suicide attempts (Māori 6.5\%, NZ European 2.7\%) and poorer general wellbeing (Māori 10.5\%, NZ European $6.8 \%$ ) compared to their peers (1). Suicide death rates for Māori youth are almost twice that of non-Māori (Māori suicide 17.8 people per 100,000, non-Māori 10.6 per 100,000) (8). Despite the concerning health and social impacts of poor mental health, Māori youth are significantly less likely to be able to access healthcare when needed (1) and frequently experience mental health stigma (9) and ethnic discrimination (10).

Given the well documented mental health disparities of Māori youth, there remains little published evidence on why these disparities persist or how best to address them. Measuring the impact of structural racism, inter-generational trauma and the colonizing stress on youth remains complex. Lawson-Te Aho (11) suggests the impact of colonization for contemporary Māori youth has contributed to a breakdown of traditional cultural structures; leaving a legacy of hopelessness and loss of meaning. She also asserts that when "kinship-based cultural identity is intact and relationships are positive and functional, suicide can be prevented" (11, p.128). While there is evidence that whānau and community relationships are protective for mental health concerns (12-15) there is much less evidence to support the assertion that Māori cultural identity is also protective $(16,17)$.

There is conflicting literature regarding the positive influence of cultural identity on health outcomes for Māori. Brougham and Harr (18) found that high levels of collectivism, cultural knowledge and language led to improved mental wellbeing. Coupe's (19) study also found that a secure Māori identity, healthy connections to social groups and a sense of belonging were protective against suicide. However, Broughton as cited in Tatz (20) reported that some Māori youth who were immersed in Māori culture, still died from suicide. In contrast, Marie et al. (21) found that sole Māori ethnicity was associated with increased exposure to childhood physical abuse and inter-parental violence. Given the lack of cohesive literature and evidence in this area, the aim of this project was to identify whether a strong Māori cultural identity was associated with improved wellbeing for Māori youth.

\section{MATERIALS AND METHODS}

Youth'12 is a nationally representative, anonymous crosssectional survey of New Zealand secondary school students aged approximately 12-19 years old. The survey utilized a two-stage cluster sample design, with a third of all secondary schools in New Zealand invited to participate and then $20 \%$ of each participating school's roll was randomized and invited to participate. This accounted for approximately $3-4 \%$ of the total NZ secondary school population. The school response rate was $72.8 \%$ and student response rate was $68 \%$ (22). Ethical approval was gained from the University of Auckland Human Participants Ethics Committee (UAHPEC) (Ref 2011/206).

The Youth'12 questionnaire administered via Multi-Media Computer Administered Survey Instrument (MCASI) (23) on internet tablets was based on the Youth2000 survey series questionnaires in 2001 and 2007 available at www. youthresearch.auckland.ac.nz. There were nine main domains in the survey that addressed the wider determinants of wellbeing for NZ youth including variables relevant to this paper; ethnic specific questions, mental health, family wellbeing and social connections. The questionnaire was administered in English and te reo Maori (Māori language) options.

\section{Demographic Measures}

These were based on self-report for age, sex ("male" and "female" only) and ethnicity. Ethnicity was based on the New Zealand census standard 2001/2006 ethnicity question: "Which ethnic group do you belong to?" Students were able to choose more than one response from the list of 23 options used in the statistical standard for ethnicity (24). We have utilized the New Zealand ethnic prioritization method (25). Prioritized ethnicity is based on the hierarchy; Māori $>$ Pacific $>$ Asian $>$ Other $>$ New Zealand European (NZE). NZDep combines variables from census data related at the neighborhood level to income, home ownership, financial support, employment, qualifications, living space, communication and transport, to reflect levels of deprivation (26).

\section{MCIS Scale Development}

A literature review was undertaken to identify the components of Māori cultural identity. Relevant research came from a selection

TABLE 1 | Descriptive participant characteristics by level of cultural identity (unweighted).

\begin{tabular}{lcccc}
\hline & $\begin{array}{c}\text { Total sample } \\
\text { (including māori) } \\
\boldsymbol{n ( \% )}\end{array}$ & $\begin{array}{c}\text { Total māori } \\
\boldsymbol{n}(\%)\end{array}$ & $\begin{array}{c}\text { High cultural } \\
\text { identity } \\
\boldsymbol{n}(\%)\end{array}$ & $\begin{array}{c}\text { Low cultural } \\
\text { identity } \\
\boldsymbol{n ( \% )}\end{array}$ \\
\hline AGE & & & & \\
13 years & $1,838(21.7)$ & $406(24.3)$ & $219(26.7)$ & $187(21.9)$ \\
14 years & $1,896(22.3)$ & $429(25.6)$ & $226(27.6)$ & $203(23.8)$ \\
15 years & $1,755(20.7)$ & $350(20.9)$ & $168(20.5)$ & $182(21.3)$ \\
16 years & $1,578(18.6)$ & $274(16.4)$ & $124(15.1)$ & $150(17.6)$ \\
$\geq 17$ & $1,422(16.8)$ & $215(12.8)$ & $83(10.1)$ & $132(15.5)$ \\
SEX & & & & \\
Male & $3,874(45.6)$ & $790(47.2)$ & $373(45.5)$ & $417(48.8)$ \\
Female & $4,623(54.4)$ & $884(52.8)$ & $447(54.5)$ & $437(51.2)$ \\
NZ DEP & & & & \\
Low deprivation & $2,718(32.4)$ & $331(19.8)$ & $107(13.1)$ & $224(26.2)$ \\
Medium & $3,001(35.8)$ & $571(34.1)$ & $244(29.8)$ & $327(38.3)$ \\
High & $2,674(31.9)$ & $772(46.1)$ & $469(57.2)$ & $303(35.5)$
\end{tabular}

deprivation

$\begin{array}{lcccc}\text { ANY ETHNIC DISCRIMINATION } & & & \\ \text { No } & \text { NA } & 1,247(74.5) & 551(67.2) & 696(81.5) \\ \text { Yes } & & 427(25.5) & 269(32.8) & 158(18.5) \\ & 8,500 & 1,674 & 820(49.0) & 854(51.0)\end{array}$


of journal articles, gray literature, books and Māori Health Models. Four themes were identified: (1) Whanaungatanga (Collectivist Identity and Relationships) includes active participation and sense of belonging to family and various social groups (27-34). (2) Ko wai au? (Who am I?/Personal Ethnic Identity) is the concept of who you are and where you come from spiritually, mentally and physically (27-37). (3) Ngā Taonga Māori (Precious Māori Cultural Resources) includes the accessibility and participation in traditional knowledge and practices (28-34, 38-40). Lastly are the (4) Social Determinants of Wellbeing that might include socio-economic factors, history, colonization, structural, interpersonal or internalized discrimination, policy, changing demographics and media representations $(12,28,29,31,33,35,39,41-43)$. For the purposes of these analyses, the two themes Ko wai au? and Ngā Taonga Māori were utilized to guide our development of the Māori Cultural Identity Scale (MCIS) utilizing available questions from the Youth'12 national health and wellbeing survey questionnaire (Table 2).

Distributions of variables were explored, and we excluded those with high levels of missing data. Correlations between all of the variables were explored through correlation matrices, and we excluded further variables with low correlations to any of the others. With the remaining 14 cultural variables, we explored how these clustered together using factor analysis. We created a MCIS with a range of $0-14$ by summing the number of variables present for each student. We divided students into two groups using the median, and those who reported higher than the median, were coded as "high cultural identity" (8 or more items present) and "low cultural identity" (7 or fewer items).

We included the theme Social Determinants of Wellbeing as covariates and possible confounders in our analysis through the inclusion of deprivation and discrimination. Neighborhood deprivation was measured using The New Zealand Deprivation Index (NZDep2006). (26), and a discrimination variable was constructed from three questions based on earlier work (10): "Have you ever been treated unfairly (e.g., treated differently) by a teacher because of your ethnicity or ethnic group? Have you ever been treated unfairly (e.g., treated differently, kept waiting) by a health professional (e.g., doctor, nurse, dentist etc.) because of your ethnicity or ethnic group? Have you been treated unfairly (picked on, hassled, etc.) by the police because of your ethnic

TABLE 2 | Questions from the Youth'12 survey utilized to develop the Maori cultural identity scale.

\begin{tabular}{|c|c|c|c|c|c|}
\hline & Survey question & Response & $n / N$ & $\%$ & $95 \% \mathrm{Cl}$ \\
\hline Ngā Taonga Māori & $\begin{array}{l}\text { How satisfied are you with your knowledge of things } \\
\text { Māori? }\end{array}$ & $\begin{array}{l}\text { Very satisfied and } \\
\text { satisfied }\end{array}$ & $770 / 1,691$ & 45.3 & $42.2-48.4$ \\
\hline \multirow{7}{*}{$\begin{array}{l}\text { (Precious Māori Cultural } \\
\text { Resources) }\end{array}$} & Do you know your iwi (tribe or tribes)? & Yes & $1,303 / 1,700$ & 76.6 & $74.4-78.8$ \\
\hline & $\begin{array}{l}\text { Have you learnt about Māori culture, such as language, } \\
\text { songs, cultural practice or family history/ancestry } \\
\text { (whakapapa)? }\end{array}$ & Yes & $1,514 / 1,700$ & 89.1 & $87.3-90.8$ \\
\hline & Have you ever been to a tangi or unveiling? & Yes & $1,335 / 1,700$ & 78.5 & $74.6-82.4$ \\
\hline & $\begin{array}{l}\text { What languages do your parents or the people who look } \\
\text { after you usually speak? }\end{array}$ & Māori & $566 / 1,701$ & 32.9 & $28.9-37.0$ \\
\hline & $\begin{array}{l}\text { Which languages can you speak well enough to have a } \\
\text { conversation in? }\end{array}$ & Māori & $448 / 1,700$ & 26.1 & 23.6-28.7 \\
\hline & $\begin{array}{l}\text { How well are you personally able to speak Māori in } \\
\text { day-to- day conversation? By this we mean more than a } \\
\text { few words or phrases? }\end{array}$ & $\begin{array}{l}\text { Very well, Well and } \\
\text { Fairly well }\end{array}$ & 787/1,699 & 46.0 & $43.2-48.9$ \\
\hline & $\begin{array}{l}\text { How well are you personally able to speak Māori in } \\
\text { day-to- day conversation? By this we mean more than a } \\
\text { few words or phrases? }\end{array}$ & $\begin{array}{l}\text { Very well, Well and } \\
\text { Fairly well }\end{array}$ & $530 / 1,698$ & 31.0 & 28.4-33.7 \\
\hline \multirow[t]{6}{*}{$\begin{array}{l}\text { Ko wai au? (Personal Ethnic } \\
\text { Identity) }\end{array}$} & $\begin{array}{l}\text { Which is your main ethnic group (the one you identify } \\
\text { with most)? }\end{array}$ & Māori & $839 / 1,660$ & 50.2 & $46.4-54.0$ \\
\hline & $\begin{array}{l}\text { Are Māori values important to you (e.g., Whanau and } \\
\text { Hui; Family gatherings), Karakia (prayer), Wairua } \\
\text { (Spirituality) or Whakapapa (Family history)? }\end{array}$ & Very important & $662 / 1,697$ & 38.8 & $34.9-42.6$ \\
\hline & Are you proud of being Māori? & I'm very proud & $1,214 / 1,694$ & 71.3 & $68.3-74.4$ \\
\hline & $\begin{array}{l}\text { How often do you think about your ethnicity or ethnic } \\
\text { group? }\end{array}$ & Often and all the time & $671 / 1,701$ & 39.3 & $36.3-42.2$ \\
\hline & $\begin{array}{l}\text { Earlier you told us about your ethnicity. Now we would } \\
\text { like to know about other people's reaction to your } \\
\text { ethnicity. How do other people usually classify your } \\
\text { ethnic group (i.e., what ethnic group/s do other people } \\
\text { usually think you are)? (you may choose as many as you } \\
\text { need) }\end{array}$ & Māori & $1,130 / 1,701$ & 66.3 & $63.0-69.5$ \\
\hline & $\begin{array}{l}\text { How important is it to you to be recognized as a Māori } \\
\text { person? }\end{array}$ & $\begin{array}{l}\text { Very important and } \\
\text { Important }\end{array}$ & $984 / 1,694$ & 57.9 & $54.3-61.4$ \\
\hline
\end{tabular}


group?" Responses were binary (yes/no) if they had experienced any discrimination.

\section{Dependent Variables}

Three mental health outcomes utilized in these analyses were: The 5-item World Health Organization Well-Being Index (WHO-5), a valid and reliable measure of positive quality of life, with a cut-off of 13 or higher being a measure of good, very good or excellent wellbeing (44); The Reynolds Adolescent Depression Scale- Short Form (RADS- SF), a 10 item valid and reliable self-report survey, based on the DSM-III diagnostic criteria for major depressive disorder and dysthymic disorder, along with symptoms from the Research Diagnostic Criteria for Affective Disorders (45); and suicide attempt, based on one question "During the last 12 months have you tried to kill yourself (attempt suicide)?" with binary response (yes/no).

\section{Analyses}

Logistic regression models were utilized, to explore the associations between MCIS and the three mental health outcomes. We adjusted these models sequentially for age and sex, neighborhood deprivation, and discrimination. We explored for effect modification by age and sex by including interaction terms in models. Results are presented as weighted percentages, odds ratios with $95 \%$ confidence intervals.

\section{RESULTS}

Of the 91 schools that participated, 87 had Māori students, and of the 8,500 participating students, 1,701 identified as Māori. Māori youth comprise approximately $19.7 \%$ of the total New Zealand secondary school population in 2011 and the Youth'12 survey achieved a representative sample of $20.1 \%$ Māori. Māori students who participated in the Youth'12 survey had a slightly higher proportion of females (52.8\%), and a higher proportion of students were 15 years or younger $(70.8 \%)$ (Table 1). Māori were more likely to be living in areas with higher levels of deprivation, with $80.2 \%$ of the sample living in medium or highly deprived areas. A quarter $(25.5 \%)$ of all Māori participants reported that they had experienced some form of ethnic discrimination at school, in health care or with the police. There were missing data from 27 participants (1.6\%) for variables included in the analyses (age, sex, NZ Dep, discrimination and cultural identity), and these were excluded from all analyses. In terms of mental health outcomes, $75.1 \%$ of students reported good wellbeing based on WHO5 wellbeing scale $(n=1,219 / 1,623), 13.8 \%$ report significant depressive (RADS-SF) symptoms $(n=219 / 1,591)$ and $6.5 \%$ reported a suicide attempt in the previous twelve months $(n=1,071,638)$.

In general, there were high levels of Māori cultural identity concepts evident in the Youth'12 survey; Ngā Taonga Māori (Precious Māori Cultural Resources) and Ko wai au? (Who am I?/Personal Ethnic Identity) (Table 2). Items in these two

TABLE 3 | Associations between Maori cultural identity and WHO wellbeing score.

\begin{tabular}{|c|c|c|c|c|c|}
\hline & $\begin{array}{c}\text { Wellbeing } \\
n(\%)\end{array}$ & $\begin{array}{c}\text { Model } 1 \\
\text { OR (95\% Cl) }\end{array}$ & $\begin{array}{c}\text { Model } 2 \\
\text { aOR }(95 \% \mathrm{CI})\end{array}$ & $\begin{array}{c}\text { Model } 3 \\
\text { aOR }(95 \% \mathrm{Cl})\end{array}$ & $\begin{array}{c}\text { Model } 4 \\
\text { aOR (95\% Cl) }\end{array}$ \\
\hline \multicolumn{6}{|c|}{ MĀORI CULTURAL IDENTITY } \\
\hline Low cultural identity & 604/835 (72.3) & 1 & 1 & 1 & 1 \\
\hline High cultural identity & $615 / 788(78.1)$ & $1.37(1.07-1.76)$ & $1.41(1.09-1.83)$ & $1.37(1.06-1.77)$ & $1.53(1.18-2.01)$ \\
\hline \multicolumn{6}{|l|}{ AGE } \\
\hline$\leq 13$ years & 308/386 (79.8) & 1 & 1 & 1 & 1 \\
\hline 14 years & $305 / 415(73.5)$ & $0.71(0.50-1.00)$ & $0.70(0.49-0.98)$ & $0.69(0.49-0.98)$ & $0.70(0.49-1.00)$ \\
\hline 15 years & 265/344 (77.0) & $0.84(0.61-1.17)$ & $0.86(0.62-1.19)$ & $0.86(0.62-1.19)$ & $0.88(0.63-1.22)$ \\
\hline 16 years & $186 / 269(69.1)$ & $0.57(0.38-0.85)$ & $0.57(0.38-0.84)$ & $0.57(0.38-0.85)$ & $0.60(0.40-0.89)$ \\
\hline$\geq 17$ & 155/209 (74.2) & $0.73(0.50-1.05)$ & $0.79(0.53-1.18)$ & $0.80(0.54-1.18)$ & $0.80(0.54-1.21)$ \\
\hline \multicolumn{6}{|l|}{ SEX } \\
\hline Male & $643 / 760(84.6)$ & 1 & 1 & 1 & 1 \\
\hline Female & $576 / 863(66.7)$ & $0.36(0.29-0.46)$ & $0.35(0.28-0.45)$ & $0.36(0.28-0.45)$ & $0.33(0.26-0.42)$ \\
\hline \multicolumn{6}{|c|}{ NEW ZEALAND DEPRIVATION INDEX } \\
\hline Low deprivation (1-3) & 231/322 (71.7) & 1 & & 1 & 1 \\
\hline Medium deprivation (4-7) & $414 / 558(74.2)$ & $1.12(0.80-1.58)$ & & $1.12(0.80-1.58)$ & $1.12(0.80-1.57)$ \\
\hline High deprivation (8-10) & $574 / 743(77.3)$ & $1.33(1.00-1.77)$ & & $1.20(0.88-1.63)$ & $1.22(0.91-1.65)$ \\
\hline \multicolumn{6}{|c|}{ ANY ETHNIC DISCRIMINATION } \\
\hline No & $943 / 1,218(77.4)$ & 1 & & & 1 \\
\hline Yes & 276/405 (68.2) & $0.63(0.50-0.79)$ & & & $0.50(0.39-0.65)$ \\
\hline Total & $1,219 / 1,623(75.1)$ & & & & \\
\hline
\end{tabular}

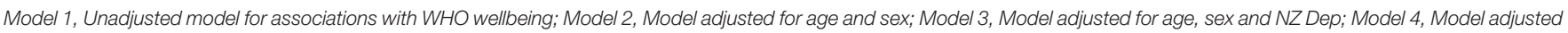
for age, sex, NZ Dep and discrimination. 
themes were highly correlated, and we combined them into one Māori Cultural Identity Scale (MCIS). Using the MCIS scale, $49.0 \%$ of participants reported having eight or more cultural identity variables (Table 1). Younger students, female students and those living in areas of high deprivation reported higher levels of cultural identity. More students who had high cultural identity had reported experiences of discrimination. There was no evidence for effect modification of the association between cultural identity and mental health outcomes by age or sex.

In univariate analyses, there was a strong association between Māori Cultural Identity and WHO-5 Wellbeing scores (OR 1.37 95\% CI 1.07-1.76) (Table 3, Model 1). Being younger, male and poorer was also associated with higher WHO wellbeing scores, while experience of discrimination was associated with lower wellbeing (OR 0.63, CI 0.50-0.79). Adjusting for age, sex, and NZ Deprivation, did not alter the relationship between cultural identity and wellbeing (Table 3, Models 2 and 3). However, after adjusting for experience of discrimination (Table 3, Model 4), the relationship between cultural identity and wellbeing became stronger, suggesting that discrimination confounded the association, with those reporting high cultural identity also being more likely to report discrimination, and those reporting discrimination being more likely to report poor wellbeing.

In univariate analyses looking at the association between Māori Cultural Identity and depressive symptoms, high cultural identity was associated with lower levels of depression (Table 4, Model 1). Female students (OR 2.31, CI 1.69-3.17) and those who experienced discrimination (OR 1.72, CI 1.24-2.40) were much more likely to have depressive symptoms. Similar to WHO-5 wellbeing, adjusting for age, sex and NZ Dep had little effect on the association between cultural identity and depressive symptoms (Table 4, Models 2 and 3), while adjusting for experience of discrimination strengthened the relationship (OR 0.53, CI 0.38-0.73) (Table 4, Model 4).

In univariate analyses looking at the association between Māori Cultural Identity and attempted suicide, there was no evidence for an association (Table 5, Model 1). Only female students (OR 2.96, CI 1.88-4.65) and those experiencing discrimination were more likely to have attempted suicide (OR 2.23, CI 1.59-3.14). Those students living in neither low nor high deprivation areas were less likely to have made a suicide attempt (OR 0.54, CI 0.29-1.00). After adjusting for age, sex and deprivation there remained no evidence for an association between cultural identity and suicide attempt (Table 5, Models 2 and 3). Adjusting for discrimination had a larger effect on the association between cultural identity and suicide attempts, but the relationship was still not significant (OR 1.14, CI 0.71-1.84) (Table 5, Model 4).

\section{DISCUSSION}

In this large, nationally representative study of indigenous Māori students from mainstream education, we found that a strong sense of a Māori cultural identity was associated with improved wellbeing and reduced serious depressive symptoms. Ethnic discrimination was found to confound the relationship between mental health wellbeing and cultural identity, and associated with poorer wellbeing, increased depressive symptoms and suicide attempts amongst Māori students.

TABLE 4 | Associations between Maori Cultural Identity and symptoms of depression (using RADS-SF score).

\begin{tabular}{|c|c|c|c|c|c|}
\hline & $\begin{array}{c}\text { Depressive } \\
\text { symptoms } \\
n(\%)\end{array}$ & $\begin{array}{c}\text { Model } 1 \\
\text { OR }(95 \% \mathrm{CI})\end{array}$ & $\begin{array}{c}\text { Model } 2 \\
\text { aOR }(95 \% \mathrm{Cl})\end{array}$ & $\begin{array}{c}\text { Model } 3 \\
\text { aOR }(95 \% \mathrm{Cl})\end{array}$ & $\begin{array}{c}\text { Model } 4 \\
\text { aOR (95\% Cl) }\end{array}$ \\
\hline Low cultural identity & 135/824 (16.4) & 1 & 1 & 1 & 1 \\
\hline High cultural identity & $84 / 767(11.0)$ & $0.62(0.47-0.82)$ & $0.58(0.43-0.77)$ & $0.60(0.44-0.81)$ & $0.53(0.38-0.73)$ \\
\hline \multicolumn{6}{|l|}{ AGE } \\
\hline 15 years & $56 / 331(16.9)$ & $1.40(0.91-2.14)$ & $1.36(0.89-2.09)$ & $1.37(0.89-2.11)$ & $1.36(0.87-2.11)$ \\
\hline 16 years & $33 / 266(12.4)$ & $0.94(0.60-1.47)$ & $0.90(0.56-1.44)$ & $0.90(0.56-1.44)$ & $0.84(0.52-1.36)$ \\
\hline$\geq 17$ & 19/203 (9.36) & $0.69(0.39-1.20)$ & $0.60(0.34-1.07)$ & $0.60(0.34-1.07)$ & $0.58(0.32-1.04)$ \\
\hline \multicolumn{6}{|l|}{ SEX } \\
\hline Male & 64/734 (8.7) & 1 & 1 & 1 & 1 \\
\hline Female & 155/857 (18.1) & $2.31(1.69-3.17)$ & $2.41(1.76-3.31)$ & $2.41(1.75(3.32))$ & $2.61(1.86-3.64)$ \\
\hline \multicolumn{6}{|c|}{ ANY ETHNIC DISCRIMINATION } \\
\hline No & $144 / 1,201(12.0)$ & 1 & & & 1 \\
\hline Yes & $75 / 390$ (19.2) & $1.72(1.24-2.40)$ & & & $2.22(1.55-3.18)$ \\
\hline Total & $219 / 1,591(13.8)$ & & & & \\
\hline
\end{tabular}

Model 1, Unadjusted model for associations with WHO wellbeing; Model 2, Model adjusted for age and sex; Model 3, Model adjusted for age, sex and NZ Dep; Model 4, Model adjusted for age, sex, NZ Dep and discrimination. 
TABLE 5 | Associations between Maori cultural identity and attempted suicide within the previous 12 months.

\begin{tabular}{|c|c|c|c|c|c|}
\hline & $\begin{array}{l}\text { Attempted } \\
\text { suicide } \\
n(\%)\end{array}$ & $\begin{array}{c}\text { Model } 1 \\
\text { OR }(95 \% \text { Cl) }\end{array}$ & $\begin{array}{c}\text { Model } 2 \\
\text { aOR }(95 \% \mathrm{Cl})\end{array}$ & $\begin{array}{c}\text { Model } 3 \\
\text { aOR }(95 \% \mathrm{Cl})\end{array}$ & $\begin{array}{c}\text { Model } 4 \\
\text { aOR }(95 \% \mathrm{Cl})\end{array}$ \\
\hline Low cultural identity & 46/840 (5.5) & 1 & 1 & 1 & 1 \\
\hline High cultural identity & $61 / 798(7.6)$ & $1.42(0.93-2.16)$ & $1.34(0.88-2.03)$ & $1.34(0.84-2.13)$ & $1.14(0.71-1.84)$ \\
\hline \multicolumn{6}{|l|}{ AGE } \\
\hline 15 years & 25/344 (7.3) & $1.20(0.67-2.14)$ & $1.22(0.68-2.19)$ & $1.25(0.70-2.22)$ & $1.19(0.65-2.16)$ \\
\hline 16 years & $12 / 269(4.5)$ & $0.73(0.33-1.62)$ & $0.76(0.34-1.67)$ & $0.77(0.35-1.70)$ & $0.72(0.32-1.60)$ \\
\hline$\geq 17$ & $11 / 208(5.3)$ & $0.83(0.41-1.71)$ & $0.85(0.41-1.74)$ & $0.86(0.42-1.77)$ & $0.85(0.41-1.75)$ \\
\hline \multicolumn{6}{|l|}{ SEX } \\
\hline Male & 26/769 (3.4) & 1 & 1 & 1 & 1 \\
\hline Female & 81/869 (9.3) & $2.96(1.88-4.65)$ & $2.96(1.87-4.68)$ & $3.02(1.91-4.79)$ & $3.35(2.07-5.41)$ \\
\hline \multicolumn{6}{|c|}{ ANY ETHNIC DISCRIMINATION } \\
\hline No & $63 / 1,225(5.1)$ & 1 & & & 1 \\
\hline Yes & $44 / 413(10.7)$ & $2.23(1.59-3.14)$ & & & $2.47(1.71-3.58)$ \\
\hline Total & $107 / 1,638(6.5)$ & & & & \\
\hline
\end{tabular}

Model 1, Unadjusted model for associations with WHO wellbeing; Model 2, Model adjusted for age and sex; Model 3, Model adjusted for age, sex and NZ Dep; Model 4, Model adjusted for age, sex, NZ Dep and discrimination.

These findings are supportive of earlier work that found a strong sense of cultural identity is protective for mental health outcomes $(18,19,40)$. Indigenous peoples have always asserted that a strong sense of cultural identity and pride was intimately linked to wellbeing; but through colonization these have been, and continue to be devalued by dominant cultural perspectives $(17,28,46)$. Ethnic discrimination was common (25.5\%) amongst Māori students attending mainstream education in New Zealand, and associated with poorer mental health. The strong effect of discrimination and lesser influence of socio-economic deprivation for suicide attempts (medium level deprivation was protective) is an important finding and differs from previous literature (47). Previously research has emphasized socio-economic factors as a strong influence for health inequity in mental health outcomes for Maori; however our finding suggests that while socio-economic factors are important, experiences of discrimination may be more powerful in mediating mental health access. This has been previously reported among African American males, where discrimination was a more powerful indicator of suicide attempt than socioeconomic status (48). We believe that ethnic discrimination is likely to be a strong contributor to the perpetual disadvantage in our health system among Māori populations (49-53). We recommend any future suicide prevention research must collect and analyse ethnic discrimination data to enhance explanatory understandings of suicide among indigenous and minority populations.

Of interest, is the finding that students who live with socioeconomic deprivation have stronger WHO-5 wellbeing scores. It may be as Bécares et al. (41) found, that living in poorer communities that have high ethnic density was associated with positive wellbeing, and possibly attributed to reduced exposure to discrimination, increased social supports and increased access to various cultural resources. Conversely, poor students living in affluent neighborhoods experienced higher levels of depressive symptoms compared to poor students living in poor neighborhoods, reflecting the psychosocial stress of perceived socioeconomic incongruity as well as poorer access to social networks (54). Harris et al. (55) also reported that socially assigned ethnicity or being classified by others as "White" was associated with health advantage reinforcing that structural and interpersonal racism in healthcare is harmful.

The measurement of cultural and ethnic identity in quantitative research is challenging. As we reviewed the literature, we identified some concerning practices that were flawed theoretically and offensive to Māori researchers. For example, the practice of comparing "sole Māori" vs. "Māori/other identity" as a proxy for "strength of cultural identity" (21) has no theoretical or methodological foundation. Māori do not use "blood quantum" measures to define who we are or identify how strongly we identify as Māori. An example of this type of damaging ideology in well regarded research claims Māori specific cultural programming as "not evidence-based and largely ideologically driven" and concluded that "[e]ven though such policies are no doubt well intentioned and observe statutory requirements unique to the New Zealand context ... they must be exposed to ongoing critical scrutiny and empirical evaluation" (21, p. 167). This example highlights that privileging of knowledge from dominant culture academia, using racist interpretations that systematically undermine Māori knowledge 
and experiences. These practices hinder efforts to introduce and expand effective kaupapa Māori strategies (incorporating the knowledge, skills, attitudes and values of Māori society) in the New Zealand context (56), and must be challenged through anti-racism praxis (57).

As with all cross-sectional studies, this study was unable to infer causality. A further limitation is that these findings cannot be generalized to all Māori youth, as those who attend Wharekura (Māori language immersion Secondary Schools), Alternative Education (58) or are not enrolled in any schooling are not represented in these data and are likely to have greater risks. Also of note, is that at age 16 years, students can leave school in New Zealand. Given Māori are more likely to drop out of education, it may be that our finding that younger students are at more risk may be an artifact due to older Maori students no longer being in full-time education. There are also limitations with the measurement of socio-economic deprivation utilizing the NZ Dep2006 as these are based on population level census and not sensitive to individual/family level measures. Finally, the measurement of Māori cultural identity is challenging to measure in quantitative research and in some cases has been successful (34). The Youth'12 survey had limited options available for the development of a comprehensive MCIS scale based on dimensions identified in the literature. In addition, while this is a nation-wide study, the cultural identities of youth in various rohe (areas/regions and tribal communities) throughout New Zealand may not be adequately represented in the MCIS measure. Further research is required to explore the nuanced and contemporary knowledge of Maori youth cultural identities and to broaden the identity scale to include the concepts of whanaungatanga (collectivist identities and relationships).

In conclusion, Māori youth mental health is complex and multi-dimensional with multiple contributing factors embedded in cultural, historical, spiritual, physiological, psychological, structural and social domains. Our findings suggest that public health programmes and services that genuinely seek to address equity for Māori youth, will ensure cultural programming and policies that are culturally and developmentally specific, as

\section{REFERENCES}

1. Crengle S, Clark TC, Robinson E, Bullen P, Dyson B, Denny S, et al. The Adolescent Health Research Group. The health and wellbeing of Māori New Zealand secondary school students in 2012 - Te Ara Whakapiki Taitamariki: Youth'12. Auckland: The University of Auckland; The Adolescent Health Research Group (2012).

2. Fleming TM, Clark TC, Denny S, Bullen P, Crengle S, Peiris-John R, et al. Stability and change in the mental health of New Zealand secondary school students 2007-2012: results from the national adolescent health surveys. Aust N Z J Psychiatr. (2014) 48:472-80. doi: 10.1177/0004867413 514489

3. McDonald GK, Healey MD, Hii J, Szymanska KE, Davison J, Anderson AJ, et al. NZ Child and Youth Mortality Review Committee 11th Data Report 2010 2014. University of Otago: NZ Child and Youth Mortality Review Committee (2015). Report No.: 11 Available online at: https://www.hqsc.govt.nz/assets/ CYMRC/Publications/eleventh-data-report-2010-2014.pdf.

4. Mental Health Commission. (PO Box 12479, Wellington, New Zealand). Child and youth mental health and addictions report. Wellington: Mental Health core components of any mental health and suicide prevention strategy. Given the high rates of suicide and persistent inequity, we must support the continued reclaiming of traditional Māori knowledge and practices by contemporary Māori youth to heal, connect and give meaning to their lives as highlighted in The Turamarama Declaration (59). In parallel, there must be structural commitment to disrupt the status quo research, policies, programmes and service provision that perpetuate discrimination and result in inequitable outcomes for Māori. Mauri Ora.

\section{AUTHOR CONTRIBUTIONS}

AW conducted the literature review, led the identification of survey variables for MCIS scale, drafted the outline of the manuscript and contributed to the analysis and interpretation. TC was principal investigator for the Youth'12 study, had oversight of the literature review, data analysis, interpretation and led the writing of the paper, structure, editing and discussion. SL contributed to the overall design of the paper, led the analysis and interpretation of data and contributed to the discussion and overall paper. All authors contributed to drafting and TC and SL did critical revisions, approved the final version for publication, and agreed to be accountable for all aspects of the work in ensuring that questions related to the accuracy or integrity of any part of the work are appropriately investigated and resolved.

\section{ACKNOWLEDGMENTS}

We gratefully acknowledge the work done by the Adolescent Health Research Group in the Youth' 12 project. Ethical approval for the cross-sectional study was from the University of Auckland Human Ethics Committee Ref. 2011/206. The Youth'12 project was funded by the Ministries of Youth Development, Social Development, Health, Education and Justice, the Department of Labour, the Families Commission and the Health Promotion Agency (formerly ALAC).

Commission (2011). Available online at: https://www.mentalhealth.org. nz/assets/ResourceFinder/Child-and-youth-mental-health-and-addiction2011-MHC.pdf.

5. Baxter J, Kingi T, Tapsell R, Durie M, Mcgee MA, New Zealand Mental Health Survey Research Team. Prevalence of mental disorders among Māori in te rau hinengaro: the New Zealand mental health survey. Aust NZ J Psychiatr. (2006) 40:914-23. doi: 10.1080/j.1440-1614.2006.01911.x

6. Baxter J. Mental health: psychiatric disorder and suicide In: Robson B, Harris R, editors. Hauora: Mãori Standards of Health IV. A Study of the Years 20002005. Wellington: Te Ropu Rangahau Hauora a Eru Pomare (2007) p. 121-39. Available online at: https://www.otago.ac.nz/wellington/otago067746.pdf.

7. Rivas-Drake D, Seaton EK, Markstrom C, Quintana S, Syed M, Lee $\mathrm{RM}$, et al. Ethnic and racial identity in adolescence: Implications for psychosocial, academic, and health outcomes. Child Dev. (2014) 85:40-57. doi: $10.1111 /$ cdev.12200

8. Suicide Mortality Review Committee. (PO Box 25496, Wellington 6146, New Zealand). Ngā Rāhui Hau Kura: Suicide Mortality Review Committee Feasibility Study 2014-15. Report to the Ministry of Health 31 May 2016. Wellington: Health Quality \& Safety Commission (2016) Available 
online at: https://www.hqsc.govt.nz/assets/SUMRC/PR/SuMRC-full-reportMay-2016.pdf.

9. Curtis C. Youth perceptions of suicide and help-seeking:'They'd think I was weak or "mental"'. J Youth Stud. (2010) 13:699-715. doi: 10.1080/13676261003801747

10. Crengle S, Robinson E, Ameratunga S, Clark TC, Raphael D. Ethnic discrimination prevalence and associations with health outcomes: data from a nationally representative cross-sectional survey of secondary school students in New Zealand. BMC Public Health (2012) 12:45. doi: 10.1186/1471-2458-12-45

11. Lawson-Te Aho K, Liu JH. Indigenous suicide and colonization: the legacy of violence and the necessity of self-determination. Int J Conflict Violence (2010) 4:124-33. doi: 10.4119/UNIBI/ijcv.65

12. Clark TC, Robinson E, Crengle S, Fleming T, Ameratunga S, Denny SJ, et al. Risk and protective factors for suicide attempt among indigenous Māori youth in New Zealand: the role of family connection. Int J Indigenous Health (2011) 7:16. doi: $10.18357 /$ ijih71201112350

13. Edwards S, McCreanor T, Moewaka-Barnes H. Māori family culture: a context of youth development in counties/Manukau. Kotuitui N Z J Soc Sci Online (2007) 2:1-15. doi: 10.1080/1177083X.2007.9522420

14. Stuart J, Jose PE. The protective influence of family connectedness, ethnic identity, and ethnic engagement for New Zealand Māori adolescents. Dev Psychol. (2014) 50:1817-26. doi: 10.1037/a0036386

15. Huriwai T, Robertson PJ, Armstrong D, Kingi TP, Huata P. Whanaungatanga - a process of treatment of Māori with alcohol and drug-use related problems. Subst Use Misuse (2001) 36:1033-51. doi: 10.1081/JA-100 104488

16. Beautrais A, Collings S, Ehrhardt P, Henare K. Suicide Prevention: A Review of Evidence of Risk and Protective Factors, and Points of Effective Intervention. Wellington: Ministry of Health (2005).

17. Durie, M. Whaiora: Māori Health Development. 2nd Edn. Auckland: Oxford University Press (1998).

18. Brougham D, Haar JM. Collectivism, cultural identity and employee mental health: a study of New Zealand Māori. Soc Indicat Res. (2013) 114:1143-60. doi: 10.1007/s11205-012-0194-6

19. Coupe NM. Whakamomori: Māori Suicide [Doctor of Philosophy]. Massey University (2005).

20. Tatz C. Aboriginal suicide is different: Aboriginal Youth Suicide in New South Wales, the Australian Capital Territory and New Zealand: Towards a Model of Explanation and Alleviation. Criminology Research Council (1999).

21. Marie D, Fergusson DM, Boden JM. Ethnic identity and exposure to maltreatment in childhood: evidence from a New Zealand birth cohort. Soc Policy JN Z. (2009) 36:154-71.

22. Clark TC, Fleming T, Bullen P, Crengle S, Denny S, Dyson B, et al. Youth'12 Prevalence Tables: The health and wellbeing of New Zealand secondary school students in 2012. Auckland: The University of Auckland (2013).

23. Watson PD, Denny SJ, Adair V, Ameratunga SN, Clark TC, Crengle SM, et al. Adolescents' perceptions of a health survey using multimedia computerassisted self-administered interview. Aust N Z J Public Health (2001) 25:520-4. doi: 10.1111/j.1467-842X.2001.tb00316.x

24. Statistics New Zealand. Statistical Standard for Ethnicity. Wellington: Statistics New Zealand (2005). Available online at: http://archive.stats. govt.nz/methods/classifications-and-standards/current-classifications-andstandards-review/ethnic-nz-std-classn-2005-new-version.aspx

25. Lang, K. Measuring Ethnicity in the New Zealand Population Census. Wellington: Statistics New Zealand (2002).

26. Salmond C, Crampton P, Atkinson J. NZDep2006 Index of Deprivation Instruction Manual. Wellington: Department of Public Health, University of Otago (2007). Available online at: http://www.otago.ac.nz/wellington/ otago020337.pdf.

27. Ware F, Walsh-Tapiata W. Youth development: Māori styles. Youth Stud Aust. (2010) 29:18-29. Available online at: https://search.informit.com.au/ documentSummary; $\mathrm{dn}=568567466586735$;res=IELAPA

28. Durie, M. Mauri ora: The dynamics of Māori health. In: Cook J, editor. Singapore: Oxford University Press (2001). p. 187-217.

29. Durie A. Te aka matua: Keeping a Māori identity. In: Te Whāiti P, McCarthy M, Durie A, editors. Mai I Rangiātea. Auckland: Auckland University Press with Bridget Williams Books (1997). p. 142-62.
30. Durie M. Whanau, whanaungatanga and healthy Māori development. In: Te Whāiti P, McCarthy M, Durie A, editors. Mai I Rangiātea. Auckland: Auckland University Press with Bridget Williams Books (1997) p. 1-24.

31. Durie M. Te hoe nuku roa framework a Māori identity measure. J Polynesian Soc. (1995) 104:461-70. Available online at: http://www.jstor.org/stable/ 20706636

32. Moeke-Pickering T. Māori Identity Within Whanau: A Review of Literature. Hamilton: Univeristy of Waikato (1996).

33. Simmonds H, Harre N, Crengle S. Te Kete Whanaketanga - Rangatahi: A model of positive development for rangatahi Māori. MAI J. (2014) 3:211-26.

34. Greaves LM, Manuela S, Muriwai E, Cowie LJ, Lindsay C, Matika CM, et al. The multidimensional model of Māori identity and cultural engagement: measurement equivalence across diverse Māori groups. N Z J Psychol. (2017) 46:24-35. Available online at: http://www.psychology.org.nz/wp-content/ uploads/ Measurement-Equivalence-across-Diverse-Māori-Groups.pdf

35. Te Korowai Aroha o Aotearoa Inc. Two Whare Korero - Tipuna Whare. Whakatane: Te Korowai Aroha o Aotearoa Inc (2010).

36. Durie, M. Whaiora: Maori Health Development. Auckland: Oxford University Press (1998).

37. Pere, RTR. Te Wheke: A Celebration of Infinite Wisdom, 2nd Edn. Wairoa: Ao Ako Global Learning New Zealand with the assistance of Awareness Book Company (1997).

38. Ngaha $\mathrm{AB}$. Te Reo, a language for Māori alone? An Investigation into the Relationship Between the Māori Language and Mãori Identity [Doctoral Dissertation]. Auckland: University of Auckland (2011)

39. Ratima M, Ratima A. Indicators of Māori Child Health Status. Wellington: Ministry of Health (1997). Available online at: http://www.moh.govt.nz/ notebook/nbbooks.nsf/0/E69DA71123EF99694C256896000C901B/\$file/ indicators $\% 20$ of $\% 20$ maori\%20 child\%20health.pdf.

40. Houkamau CA, Sibley CG. Māori cultural efficacy and subjective wellbeing: a psychological model and research agenda. Soc Indicat Res. (2011) 103:379-98. doi: 10.1007/s11205-010-9705-5

41. Bécares L, Cormack D, Harris R. Ethnic density and area deprivation: Neighbourhood effects on Māori health and racial discrimination in Aotearoa/New Zealand. Soc Sci Med. (2013) 88:76-82. doi: 10.1016/j.socscimed.2013.04.007

42. McCarthy M. Raising a Māori child under a new right state In: Te Whāiti P, McCarthy M, Durie A, editors. Mai I Rangiātea. Auckland: Auckland University Press with Bridget Williams Books (1997). p. 25-38.

43. Rochford T. Whare tapa wha: A Māori model of a unified theory of health. $J$ Primary Prev. (2004) 25:41-57. doi: 10.1023/B:JOPP.0000039938.39574.9e

44. Bech P, Olsen LR, Kjoller M, Rasmussen NK. Measuring well-being rather than the absence of distress symptoms: A comparison of the SF-36 mental health subscale and the WHO-Five well-being scale. Int J Methods Psychiatr Res. (2003) 12:85-91. doi: 10.1002/mpr.145

45. Reynolds WM. The reynolds adolescent depression scale In: Hilsenroth MJ, Segal DL, editors. Coprehensive Handbook of Psychological Assessment: Vol. 2. Personality assessment. 2nd Ed. (RADS-2), Hoboken, NJ: Wiley (2004) p. 224-36.

46. Knibb-Lamouche K. Culture as a Social Determinant of Health. Commissioned paper prepared for the Institute on Medicine, Roundtable on the Promotion of Health Equity and the Elimination of Health Disparities, Seattle, WA (2012).

47. Gillies WM, Boden JM, Friesen MD, Macfarlane S, Fergusson DM. Ethnic differences in adolescent mental health problems: examining early risk factors and deviant peer affiliation. J Child Family Stud. (2017) 26:2889-99. doi: 10.1007/s10826-017-0792-7

48. Assari S, Moghani Lankarani M, Caldwell CH. Discrimination increases suicidal ideation in black adolescents regardless of ethnicity and gender. Behav Sci. (2017) 7:75.

49. Harris R, Tobias M, Jeffreys M, Waldegrave K, Karlsen S, Nazroo J. Racism and health: the relationship between experience of racial discrimination and health in New Zealand. Soc Sci Med. (2006) 63:1428-41. doi: 10.1016/j.socscimed.2006.04.009

50. Harris R, Cormack D, Tobias M, Yeh L, Talamaivao N, Minster J, Timutimu $R$. The pervasive effects of racism: experiences of racial discrimination in New Zealand over time and associations with multiple health domains. Soc Sci Med. (2012) 74:408-15. doi: 10.1016/j.socscimed.2011.11.004 
51. Houkamau CA, Stronge S, Sibley CG. The prevalence and impact of racism toward indigenous Māori in New Zealand. Int Perspect Psychol. (2017) 6:61. doi: 10.1037/ipp0000070

52. Thayer ZM, Kuzawa CW. Ethnic discrimination predicts poor self-rated health and cortisol in pregnancy: insights from New Zealand. Soc Sci Med. (2015) 128:36-42. doi: 10.1016/j.socscimed.2015.01.003

53. Krieger N. Discrimination and health inequities. Int J Health Serv. (2014) 44:643-710. doi: 10.2190/HS.44.4.b

54. Denny S, Lewycka S, Utter J, Fleming T, Peiris-John R, Sheridan J, et al. The association between socioeconomic deprivation and secondary school students' health: findings from a latent class analysis of a national adolescent health survey. Int J Equity Health (2016) 15:109.

55. Harris RB, Cormack DM, Stanley J. The relationship between sociallyassigned ethnicity, health and experience of racial discrimination for Māori: analysis of the 2006/07 New Zealand health survey. BMC Public Health (2013) 13:844. doi: 10.1186/1471-2458-13-844

56. Cormack D, Stanley J, Harris R. Multiple forms of discrimination and relationships with health and wellbeing: findings from national crosssectional surveys in Aotearoa/New Zealand. Int J Equity Health (2018) 17:26. doi: 10.1186/s12939-018-0735-y
57. Came H, Griffith D. Tackling racism as a "wicked" public health problem enabling allies in anti-racism praxis. Soc Sci Med. (2017) 199:181-8. doi: 10.1016/j.socscimed.2017.03.028

58. Clark TC, Smith J, Raphael D, Jackson C, Denny S, Fleming T, et al. Kicked out of school and suffering: the health needs of alternative education youth in New Zealand. Youth Stud Aust. (2010) 29:10.

59. Durie M. Indigenous suicide: the turamarama declaration. J Indigenous Wellbeing. (2017) 2:59-67.

Conflict of Interest Statement: The authors declare that the research was conducted in the absence of any commercial or financial relationships that could be construed as a potential conflict of interest.

Copyright (c) 2018 Williams, Clark and Lewycka. This is an open-access article distributed under the terms of the Creative Commons Attribution License (CC BY). The use, distribution or reproduction in other forums is permitted, provided the original author(s) and the copyright owner(s) are credited and that the original publication in this journal is cited, in accordance with accepted academic practice. No use, distribution or reproduction is permitted which does not comply with these terms. 